\title{
Glycogen Synthase Kinase-3 $\beta$ Haploinsufficiency Mimics the Behavioral and Molecular Effects of Lithium
}

\author{
W. Timothy 0'Brien, ${ }^{1}$ Amber DeAra Harper, ${ }^{1}$ Fernando Jové, ${ }^{1}$ James R. Woodgett, ${ }^{2}$ Silvia Maretto, ${ }^{3}$ Stefano Piccolo, ${ }^{3}$ \\ and Peter S. Klein ${ }^{1}$ \\ ${ }^{1}$ Division of Hematology-Oncology, Department of Medicine, and Howard Hughes Medical Institute, University of Pennsylvania School of Medicine, \\ Philadelphia, Pennsylvania 19104-6148, ${ }^{2}$ Ontario Cancer Institute, Toronto, Ontario, Canada M5G 2M9, and ${ }^{3}$ Histology and Embryology Section, \\ Department of Histology, Microbiology, and Medical Biotechnology, University of Padua, 35131 Padua, Italy
}

Lithium is widely used to treat bipolar disorder, but its mechanism of action in this disorder is unknown. Several molecular targets of lithium have been identified, but these putative targets have not been shown to be responsible for the behavioral effects of lithium in vivo. A robust model for the effects of chronic lithium on behavior in mice would greatly facilitate the characterization of lithium action. We describe behaviors in mice that are robustly affected by chronic lithium. Remarkably, these lithium-sensitive behaviors are also observed

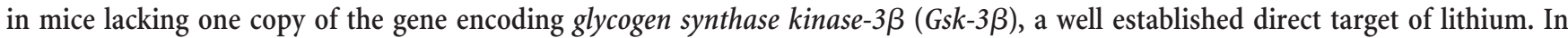
addition, chronic lithium induces molecular changes consistent with inhibition of GSK-3 within regions of the brain that are paralleled in Gsk- $3 \beta^{+I-}$ heterozygous mice. We also show that lithium therapy activates Wnt signaling in vivo, as measured by increased Wntdependent gene expression in the amygdala, hippocampus, and hypothalamus. These observations support a central role for GSK-3 $\beta$ in mediating behavioral responses to lithium.

Key words: amygdala; behavior; lithium; glycogen synthase kinase $3 \beta$; GSK-3; Wnt; T-cell factor (TCF); bipolar disorder; forced swim test; mouse

\section{Introduction}

For more than 50 years, lithium has remained the most effective treatment for bipolar disorder (BPD), but its mechanism of action is unknown. One obstacle in determining the target of lithium in affective disorders is the paucity of lithium-sensitive behavior models in mammals. Although objective modeling of mood disorders in rodents seems inherently problematic, several models representing endophenotypes associated with BPD have been investigated (Murphy, 1977; Lenox et al., 2002). Many of these studies have tested whether lithium modifies behaviors caused by other drugs. For example, amphetamine-chlordiazepoxide (Cox et al., 1971; Poitou et al., 1975; Murphy, 1977) or MAP kinase inhibitors (Einat et al., 2003) cause hyperactivity and increased exploration that is reduced in rodents pretreated with lithium. Furthermore, many previous studies have used acute dosing, although the beneficial effects of lithium in BPD are only observed after a lag of days to weeks and persist after treatment is withdrawn. This temporal profile suggests that long-term

Received 0ct. 21, 2003; revised June 10, 2004; accepted June 18, 2004.

This work was supported by a grant from the National Institute of Mental Health. We thank Ted Abel for reading this manuscript; Robert McNamara, Robert Lenox, Julie Blendy, Rita Balice-Gordon, Ash Dalvi, and Irwin Lucki for helpful suggestions; and Maya Bucan for use of acoustic startle and rotorod apparatus. We thank Gary Swain and the morphology core at the University of Pennsylvania School of Medicine, and we greatly appreciate the assistance of Ed Williamson and Jeff Golden. We also thank Linda Degenstein and Elaine Fuchs for providing the TOPGAL mice. We are indebted to Shelby Blythe for help with vibratome sections.

Correspondence should be addressed to Peter S. Klein, University of Pennsylvania School of Medicine, 415 Curie Boulevard, 364 Clinical Research Building, Philadelphia, PA 19104-6148. E-mail: pklein@mail.med.upenn.edu. DOI:10.1523/JNEUROSCI.4753-03.2004

Copyright $\odot 2004$ Society for Neuroscience $\quad$ 0270-6474/04/246791-08\$15.00/0 changes, such as alterations in gene expression, synaptic architecture, or neurogenesis, may be involved in the response to lithium (Manji et al., 1996) and may not be evident with acute lithium treatment. Some behaviors in rats have been reported to be sensitive to chronic lithium therapy, including learned helplessness (Faria and Teixeira, 1993) and activity after stress immobilization (Belmaker and Kofman, 1990; Kofman et al., 1995). However, little has been reported addressing the behavioral effects of chronic lithium per se in mice. A simple lithium-sensitive behavior in mice would greatly facilitate the study of lithium action in behavior.

Direct targets of lithium include glycogen synthase kinase-3 (GSK-3) (Klein and Melton, 1996; Stambolic et al., 1996), inositol monophosphatase (IMPase), other monophosphoesterases, and phosphoglucomutase (Berridge et al., 1989; York et al., 1995; Phiel and Klein, 2001; Gurvich and Klein, 2002). GSK-3 has been implicated in the regulation of synaptogenesis and axonal growth cone collapse (Lucas and Salinas, 1997; Lucas et al., 1998; Goold et al., 1999; Sayas et al., 1999; Burden, 2000; Hall et al., 2000; Eickholt et al., 2002; Packard et al., 2002, 2003) and is an intriguing potential target for the neuropsychiatric effects of lithium. However, IMPase is an equally plausible target (Berridge et al., 1989; Williams et al., 2002). Many of these targets are expressed in the brain and are inhibited by lithium. Therefore, alternative methods of interfering with each of these potential targets, such as gene knock-outs and novel pharmacological inhibitors, may be necessary to demonstrate that a specific target is responsible for the behavioral effects of lithium. 
We investigated the effect of lithium in a battery of standard behavioral tests in mice (Crawley and Paylor, 1997). We found that lithium alters specific behaviors in a manner that is paralleled

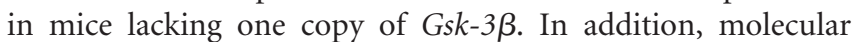
changes associated with the inhibition of GSK-3 are observed in vivo in both lithium-treated and Gsk-3$\beta^{+/-}$mice. Lithium also activates Wnt-dependent transcription in adult brain. These data provide strong genetic support for the hypothesis that lithium affects mouse behaviors through direct inhibition of GSK-3 $\beta$.

\section{Materials and Methods \\ Mice}

C57/B6 mice (Jackson Laboratories, Bar Harbor, ME), 40-50 d of age, were housed two to three per cage in $12 \mathrm{hr}$ light/dark cycles and were allowed $10 \mathrm{~d}$ to acclimate to the colony room before experiments began. Gsk-3 $\beta$ knock-out mice were maintained in the C57/B6 background as described previously (Hoeflich et al., 2000). The BAT-gal reporter mouse line was described previously (Maretto et al., 2003). All animal experimentation was reviewed and approved by the Institutional Animal Care and Use Committee and the University of Pennsylvania Laboratory Animal Resource Committee.

\section{Lithium dosing and testing schedule}

The mice were randomly assigned to three groups ( $n$ for each experiment is indicated in the figure legends). A control group was allowed free access to water and standard lab chow throughout the experiment. For lithium chloride $(\mathrm{LiCl})$ treatment, mice received chow with $0.2 \% \mathrm{LiCl}$ (Harlan Teklab, Madison, WI) for $5 \mathrm{~d}$ followed by $0.4 \% \mathrm{LiCl}$ chow for an additional $10 \mathrm{~d}$ (see Fig. 1A). For dose-response experiments, a second lowdose group of mice was maintained on $0.2 \% \mathrm{LiCl}$ throughout the experiment. All mice were given a supplemental drinking solution of $450 \mathrm{~mm}$ sodium chloride. Behavior tests began on day 10 . The test schedule was as follows: day 10, Porsolt's forced swim test (FST); day 12, hole board exploratory behavior; day 14 , elevated zero maze. To rule out an order effect in this schedule, each behavior test was performed independently with similar results. Males and females were tested independently with similar results, and the data were combined. On day 15 , the mice were killed. Trunk blood was collected, and serum lithium was measured with a flame photometer (Department of Pathology and Laboratory Medicine, University of Pennsylvania, Philadelphia, PA). The frontal cortex, hippocampus, hypothalamus, and cerebellum were dissected and frozen at $-80^{\circ} \mathrm{C}$ until processed for Western blot analysis. All behavior experiments and tissue isolation took place between 8:30 A.M. and 12:30 P.M. To test whether the behavioral effects persisted after lithium was removed from the diet, mice were either treated with lithium and control diets as described above or were given the $0.2 \% / 0.4 \% \mathrm{LiCl}$ diet beginning $2 \mathrm{~d}$ earlier and after $10 \mathrm{~d}$ were switched to the control diet for $2 \mathrm{~d}$ to allow the drug to wash out before behavior testing. A similar schedule was used in testing Gsk-3 $\beta^{+/-}$heterozygous mice. Animals were initially divided into four groups: wild-type littermates of the Gsk- $3 \beta^{+/-}$mice, wild-type mice on the $0.2 \% / 0.4 \% \mathrm{LiCl}$ described

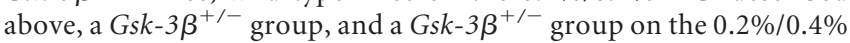
$\mathrm{LiCl}$ diet.

\section{Behavior test protocols}

Porsolt's forced swim test. Mice were individually placed in a $46 \times 22 \mathrm{~cm}$ diameter glass cylinder filled to $\sim 20 \mathrm{~cm}$ with $22-25^{\circ} \mathrm{C}$ water. Three mice at a time were videotaped with a cardboard separator between the cylinders. The last $4 \mathrm{~min}$ of a $6 \mathrm{~min}$ swim were graded for total time immobile by a person blind to group designation. The mouse was considered immobile when it was motionless or exerted only enough activity to keep afloat.

Exploratory behavior and open field. Exploratory behavior was assessed in a $14 \times 14$ inch arena with a lattice of 16 holes in the floor (San Diego Instruments, San Diego, CA). The arena was fitted with photocells to count the number of hole pokes in a $10 \mathrm{~min}$ trial. In addition to hole pokes, rearing, center activity, peripheral activity, and total activity were recorded. A change in exploratory behavior was defined as a change in the number of hole pokes without a change in the other activities.
Elevated zero maze. Mice were individually placed on a $5.5 \mathrm{~cm}$ wide circular track with an external diameter of $45 \mathrm{~cm}$ raised $40 \mathrm{~cm}$ above the floor (San Diego Instruments). The track had two open and two enclosed segments of equal dimensions. Mice were placed in the center of an open segment to begin a $5 \mathrm{~min}$ trial. Total distance traveled was assessed with a Poly-Track video system (San Diego Instruments). A scorer blind to the groups graded the videotaped trials for time spent in the open segments. The mouse was scored as within a segment when all four paws were within that segment.

To investigate state changes that may have occurred as a result of lithium treatment or Gsk-3 $\beta^{+/-}$knock-out (Crawley, 2000), a separate cohort of animals was tested in the open field, acoustic startle, prepulse inhibition of acoustic startle, accelerated rotorod, righting reflex, grip strength, and home cage behavior. No significant differences were observed among the groups.

\section{Data analysis}

All behavior data, serum lithium concentrations, and $\beta$-catenin protein quantitation were analyzed with a one-way ANOVA followed by a Dunn's post hoc analysis when a significant difference was found among the groups. The level of significance was set at $p<0.05$. GSK- $3 \beta$ protein expression data (see Fig. $4 B$ ) and analysis of $\beta$-galactosidase in situ activity were analyzed by the Student's $t$ test.

\section{Immunoblotting}

Frozen samples of hippocampus and hypothalamus were homogenized with a Polytron in $200 \mu$ l of $0.75 \%$ NP-40 lysis buffer (Tao et al., 1996); frontal cortex and cerebellum samples were homogenized in $350 \mu$ lof the same buffer. Protein content was determined by Bradford assay, and equal amounts of total protein from three mice per group were combined. Each sample (10 $\mu \mathrm{g}$ per lane) was analyzed by SDS-PAGE and immunoblotting; alternatively, samples from individual animals were analyzed independently ( $n=5$ for GSK-3 immunoblots; $n=6$ for $\beta$-catenin immunoblots), and band intensity in immunoblots was assessed by chemifluorescent imaging (Storm/PhosphorImager; Molecular Dynamics, Sunnyvale, CA). The antibodies used were anti-GSK-3 $\alpha / \beta$ (Calbiochem, La Jolla, CA), anti- $\beta$-catenin (Transduction Laboratories, San Diego, CA), and anti- $\beta$-tubulin (Promega, Madison, WI).

\section{LacZ assays}

BAT-gal mice were maintained for $3 \mathrm{~d}$ on $0.2 \% \mathrm{LiCl}$ and then switched to $0.4 \% \mathrm{LiCl}$ for $5 \mathrm{~d}$. Animals were then deeply anesthetized and perfused with $30 \mathrm{ml}$ of cold PBS followed by $30 \mathrm{ml}$ of fixative (2.0\% paraformaldehyde and $0.1 \%$ glutaraldehyde). Brains were postfixed in the same fixative for $1 \mathrm{hr}$ and then embedded in agarose, and $200 \mu \mathrm{m}$ sections were cut with a vibratome. The slices were washed three times in PBS and then placed in 5-bromo-4-chloro-3-indolyl- $\beta$-D-galactopyranoside (X-gal) staining solution $(1 \mathrm{mg} / \mathrm{ml} \mathrm{X}$-gal, $4 \mathrm{~mm}$ ferricyanide, $4 \mathrm{~mm}$ ferrocyanide, $2 \mathrm{mM} \mathrm{MgCl}_{2}$ in PBS). Sections from BAT-gal mice were incubated at $37^{\circ} \mathrm{C}$ for $1 \mathrm{hr}$ and then stopped with fixative solution and placed at $4^{\circ} \mathrm{C}$ overnight until pictures were taken. NIH ImageJ software was used to quantify the intensity of X-gal staining using coronal vibratome slices at a level that corresponds to Figure 45 of the study by Paxinos and Franklin (2001). Data were collected from five pairs of lithium-treated versus control mice. The mean percentage change in intensity was determined. A Student's $t$ test was used to determine differences between the groups in both the amygdala ( $n=5$ per group) and hippocampus $(n=4$ per group). One hundred percent of $\beta$-galactosidase-positive cells were neurons, as judged in $10 \mu \mathrm{m}$ sections by the following: (1) Nissl staining, (2) immunofluorescent staining with neuron-specific $\beta$-tubulin antibody (Sigma, St. Louis, MO), and (3) in the hippocampus, by the location and size of the neuronal cell bodies. Quantitative measurements were obtained at levels corresponding to Figures 47 and 50 of the mouse brain atlas in the study by Paxinos and Franklin (2001). In the dentate gyrus, 19 fields (at $600 \times$ magnification) were counted, which included $1274 \beta$-galpositive cells. In the amygdala, 12 fields (at $600 \times$ magnification) were counted, which included $208 \beta$-gal-positive cells. 
A. DOSE RESPONSE

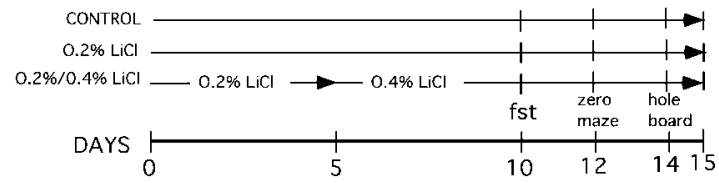

B. PERSISTENT EFFECTS OF LITHIUM

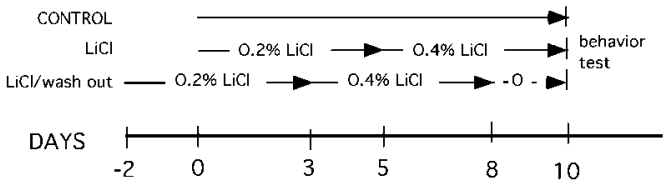

C.

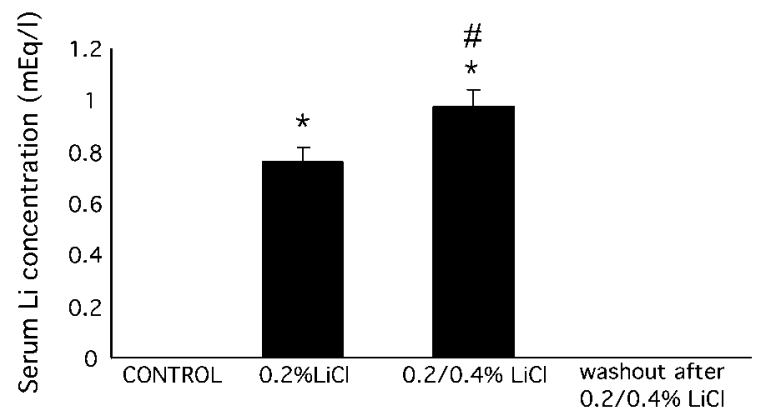

$\mathrm{LiCl}$ Dose

Figure 1. Dosing regimen and serum $\mathrm{LiCl}$ concentrations. $A$, Experimental design for the dose-response experiments. Animals were placed on a diet of $0,0.2$, or 0.2 followed by $0.4 \%$ $\mathrm{LiCl}$ in standard mouse chow for the times indicated and then were tested sequentially in the FST, elevated zero maze, and exploratory behavior (hole board) as indicated. $B$, Experimental design to test the effect of $\mathrm{LiCl}$ on behaviors after a $2 \mathrm{~d}$ drug washout. In contrast to the sequence in $A$, each behavior was tested with an independent cohort of animals to rule out an order effect. C, Serum lithium concentrations of mice from dose-response in $A .{ }^{*} p<0.05$ compared with control and washout; ${ }^{\#} p<0.05$ compared with $0.2 \% \mathrm{LiCl}$.

\section{Results}

\section{Dosage paradigm}

To identify mouse behaviors sensitive to chronic lithium, we first established a dosing regimen that would be tolerated by the mice. An oral dosing route was chosen with the expectation that dietary lithium would result in more gradual lithium uptake than would be achieved with daily injections. Lithium was phased into the diet in two steps using mouse chow formulated with $0.2 \% \mathrm{LiCl}$ followed by mouse chow containing $0.4 \% \mathrm{LiCl}$ (Fig. $1 \mathrm{~A}$ ). This dosing regimen achieved a mean serum lithium concentration of $0.97 \pm 0.07 \mathrm{mM}$ (Fig. 1C), which is within the therapeutic range for the treatment of BPD. A separate group maintained throughout the experiment on $0.2 \% \mathrm{LiCl}$ (low dose) had a mean serum lithium of $0.76 \pm 0.06 \mathrm{~mm}$. None of the lithium-treated mice in this dosing regimen showed signs of dehydration or toxicity. In addition, lithium-treated animals showed normal righting response, grip strength, performance on accelerated rotorod, and normal home cage behavior, including overall activity, grooming, and social interactions.

\section{Behavior results}

In addition to observation of home cage behavior and general state of the animals, lithium-treated and control animals were assessed in a battery of established behavioral tests to identify quantifiable traits that are sensitive to chronic lithium. Mice were tested in the Porsolt FST, exploratory behavior in a hole board apparatus, elevated zero maze, open field, acoustic startle response (ASR), prepulse inhibition of ASR, and habituation to ASR.
A.

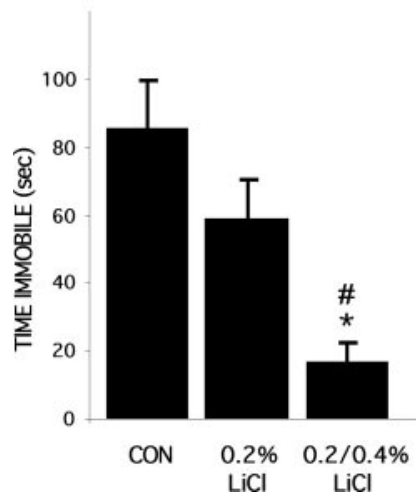

B.

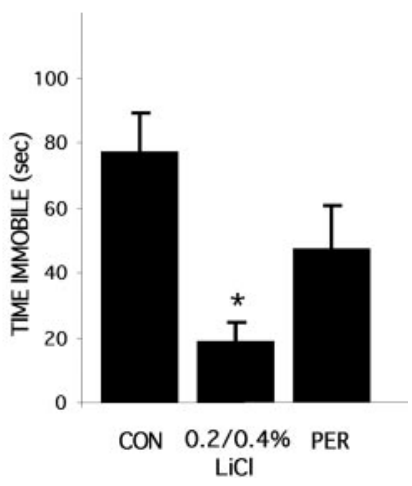

Figure 2. The effect of lithium treatment on the FST. $A$, Mice ( $n=10$ per group) were placed on a diet with increasing concentrations of $\mathrm{LiCl}$ as described in Figure $1 A$. Time immobile in the FST was measured as described in Materials and Methods. $B$, Animals were placed on the higher dose LiCl diet $(n=8)$ or control (CON) diet $(n=7)$ for $10 \mathrm{~d}$; one group $(n=8)$ was placed on the LiCl diet $2 \mathrm{~d}$ earlier, switched to control diet after $10 \mathrm{~d}$, and then tested after a $2 \mathrm{~d}$ wash out, as shown in Figure $1 B$. The intermediate response of the group removed from LiCl for $2 \mathrm{~d}$ suggests that the behavior effect persists after the drug is removed. ${ }^{*} p<0.05$ compared with control group; $\# p<0.05$ compared with $0.2 \%$ LiCl group. PER, Persistent effect of lithium after withdrawal of LiCl diet.
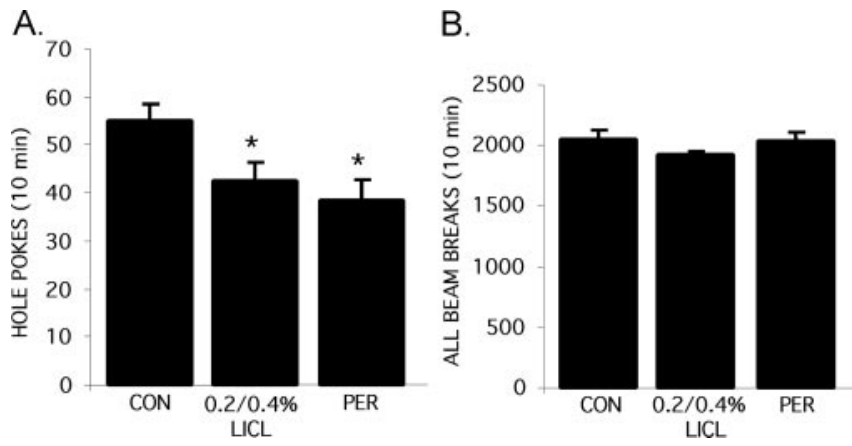

Figure 3. The effect of lithium on exploratory behavior and overall activity. Animals $(n=10$ per group) were placed on the higher dose LiCl diet, as described in Figure $1 B$, and were tested for exploratory behavior in the hole board apparatus. $A$, Frequency of hole pokes. $B$, Overall activity (including movement in center and periphery of cage as well as rearing). PER, Persistent effect of lithium after withdrawal of LiCl diet; CON, control. ${ }^{*} p<0.05$.

\section{Forced swim test}

In the FST, rodents are placed in an inescapable cylinder partially filled with water, and the time spent immobile is measured over a short time window (Porsolt et al., 1977). The FST is a reliable and widely used predictor of antidepressant efficacy and is also abnormal in mice with targeted deletions of the $5-\mathrm{HT}_{1 \mathrm{~A}}$ receptor and the noradrenaline transporter (Cryan et al., 2002). Given the reproducibility and the relative ease of this test, it has been suggested as a useful screening test for behavioral effects of novel mutations in the mouse (Crawley, 2000). Mice were therefore tested in this paradigm using $0,0.2$, and 0.2 followed by $0.4 \% \mathrm{LiCl}$ diets. A one-way ANOVA of the FST data revealed a robust effect of lithium on time immobile, and this effect was clearly dose dependent with less time immobile at the higher dose (Fig. 2A). Lithium had no effect on posture of swim or climbing behavior. The decreased time immobile in the FST was not caused by overall changes in activity, because lithium-treated mice showed similar levels of total activity in the hole board arena (Figs. 3B) and in other measures of motor activity (data not shown).

One of the hallmarks of lithium therapy in BPD is the persistence of response after lithium is discontinued, a pattern that has 


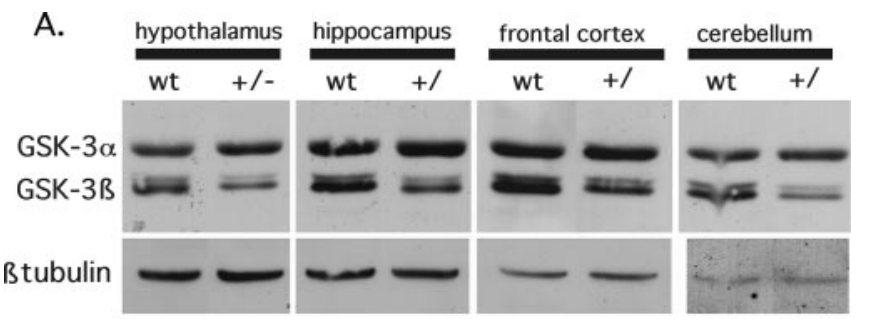

B.

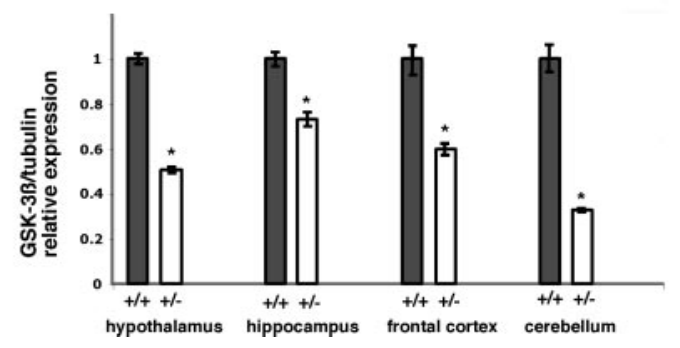

Figure 4. $A$, Reduction in GSK-3 $\beta$ protein in Gsk-3 $\beta$ heterozygous mice. Hypothalamus, hippocampus, frontal cortex, and cerebellum were isolated from adult brains of wild-type and heterozygous knock-out mice $(n=3)$ and were subjected to Western blotting for both isoforms of GSK-3. $\beta$-Tubulin serves as a loading control. B, Hypothalamus, hippocampus, frontal cortex, and cerebellum were isolated from adult brains of wild-type and heterozygous knock-out mice; GSK-3 and $\beta$-tubulin band intensities were measured independently for each animal ( $n=5$ for each group) by chemifluorescent immunoblotting and quantitation on a Storm/PhosphorImager. ${ }^{*} p \leq 0.05$ compared with untreated wild-type mice (see Materials and Methods).

suggested long-term effects of lithium, such as changes in gene expression or synaptic architecture (Manji et al., 1996). We therefore tested whether the effect of lithium in the FST persists after withdrawal of lithium. Animals were placed on the lithium diet as described above; one group began the lithium diet $2 \mathrm{~d}$ earlier and then after $10 \mathrm{~d}$ was switched back to regular chow for $2 \mathrm{~d}$ (Fig. $1 B)$. Lithium was undetectable in the serum of mice that were switched to control chow (lithium is cleared in C57/B6 mice with a half-life of $2.6 \mathrm{hr}$ ) (Wood et al., 1986). Lithium-treated animals showed decreased time immobile (Fig. $2 B$; similar to Fig. $2 A$ ); animals removed from the lithium diet for $2 \mathrm{~d}$ also showed a reduction in time immobile that approached, but did not reach, statistical significance.

\section{Exploratory behavior}

In rodents, a mixture of amphetamine and chlordiazepoxide reportedly increases exploratory behavior, and lithium has been reported to reverse this effect (Cox et al., 1971; Davies et al., 1974; Poitou et al., 1975; Murphy, 1977). To test the effect of chronic lithium treatment on exploratory behavior in the absence of other drugs, we assessed exploratory behavior in lithium-treated and control mice in a hole board apparatus, in which the number of holes explored in the floor of a chamber is recorded over 10 min (File and Wardill, 1975). Mice treated with lithium showed a decreased frequency of hole pokes (Fig. $3 A)(p<0.05)$. Furthermore, this effect persisted when lithium was removed. As with the FST, this effect of lithium on exploratory behavior is unlikely to be caused by a change in overall activity, because no significant differences were seen among the groups in center activity, peripheral activity, rearing, or total activity during the exposure to the hole board apparatus (Fig. 3B). Furthermore, although lithiumtreated mice spent more time in the open quadrants of the elevated zero maze, their overall activity in this test, as assessed by total distance traveled, was indistinguishable from controls.
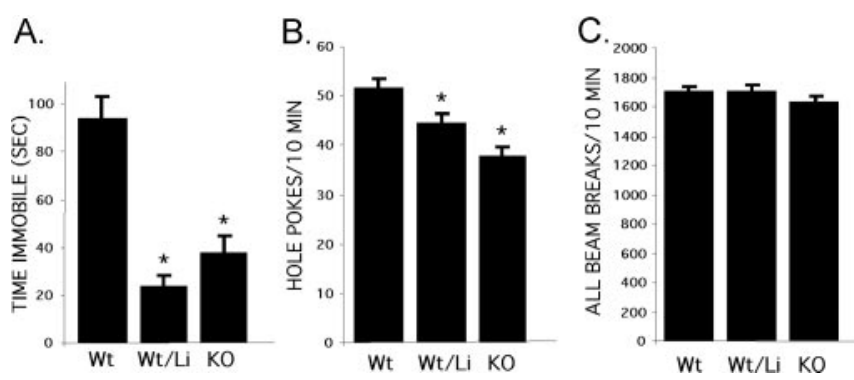

Figure 5. Heterozygous loss of Gsk-3 $\beta$ mimics the effect of lithium on the FST and hole board-exploratory behavior. $A-C, G s k-3 \beta^{+/-}$mice and wild-type littermates were tested in FST ( $A$ ) ( $n=32,31$, and 23 for Wt, Wt/Li, and K0, respectively), exploratory behavior ( $B)(n=$ 19,22 , and 18 , as noted above), and overall activity ( $C$. Wild-type littermates received $0.2 \%$ / $0.4 \% \mathrm{LiCl}$ or control diet as described in Figure $1 A .{ }^{*} p<0.05$ compared with wild-type group. wt, Wild-type littermates; wt/Li, wild-type littermates on LiCl diet; K0, Gsk-3$\beta^{+/-}$ heterozygotes.

Lithium-treated mice were also similar to controls in the ASR, prepulse inhibition of ASR, and habituation to ASR.

\section{Heterozygous loss of GSK-3 $\beta$ mimics lithium treatment}

Lithium inhibits GSK-3 in vitro (Klein and Melton, 1996) and in vivo (Stambolic et al., 1996; Hedgepeth et al., 1997). Based on this observation, we proposed that GSK-3 could be a therapeutic target of lithium in the treatment of BPD (Klein and Melton, 1996). However, although biochemical and genetic evidence strongly support a role for GSK-3 inhibition in the developmental effects of lithium, the target responsible for the behavioral effects of lithium remains an open question. We therefore wished to test genetically whether reduction of GSK-3 levels would mimic the behavioral effects of lithium. The Gsk-3 $\beta$ gene has been disrupted by targeted deletion in mice, and although $G s k-3 \beta^{-/-}$mice die

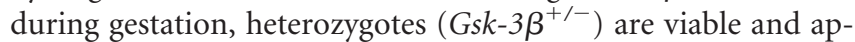
pear morphologically normal (Hoeflich et al., 2000). Mouse embryonic fibroblasts derived from Gsk-3 $\beta^{+/-}$mice express reduced levels of GSK- $3 \beta$ protein without a compensatory increase in GSK-3 $\alpha$ protein levels (Hoeflich et al., 2000), indicating a partial loss of function in Gsk-3 $\beta$ in the heterozygotes. GSK-3 activ-

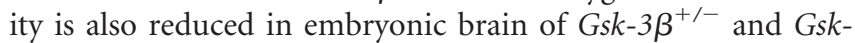
$3 \beta^{-/-}$mice, as assessed by reduced phosphorylation of fetal tau protein (data not shown). To demonstrate that heterozygous adult animals express reduced GSK- $3 \beta$ protein in the brain, we isolated frontal cortex, cerebellum, hypothalamus, and hippocampus from $G S K-3^{+/-}$mice and wild-type littermates and measured the expression of GSK- $3 \alpha$ and $\beta$ by Western blot analysis. As expected, the heterozygotes showed reduced levels of GSK-3 $\beta$ protein in all regions (Fig. $4 A, B$ ). No significant change was observed in GSK-3 $\alpha$ protein levels (Fig. $4 A$ ) or in the level of GSK-3 N-terminal phosphorylation (data not shown). We therefore tested $G s k-3 \beta^{+/-}$mice in the same battery of behavioral tests described above.

Gsk-3 $\beta^{+/-}$mice showed a markedly decreased time immobile in the FST, similar to the effect of lithium (Fig. 5A). Gsk-3 $\beta^{+/-}$ mice were also similar to lithium-treated mice in exploratory behavior, showing a reduced frequency in hole pokes (Fig. $5 B$ ). Gsk-3 $\beta^{+/-}$mice were not different from controls in total activity (Fig. 5C), ASR, or prepulse inhibition of ASR (data not shown) and, similar to the other groups, showed normal righting response, grip strength, performance on accelerated rotorod, and home cage behavior, including overall activity, grooming, and social behavior. ( $G s k-3 \beta^{+/-}$mice treated with LiCl demonstrated more marked responses than $\mathrm{LiCl}$ or $G s k-3 \beta^{+/-}$groups in the 

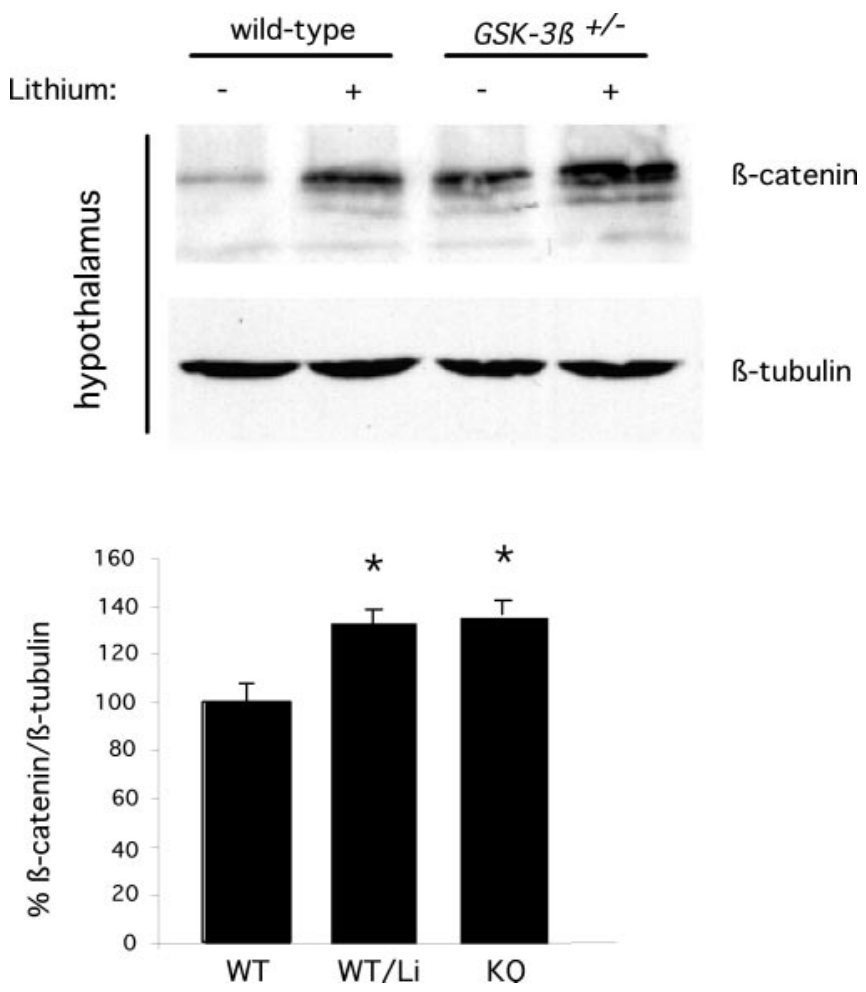

Figure 6. $\quad A, \beta$-Catenin protein levels in hypothalamus of wild-type, wild-type plus lithium, heterozygous Gsk-3 $\beta$ (Gsk-3 $\beta^{+-}$), and lithium-treated Gsk-3 $\beta^{+/-}$animals were assessed by immunoblotting. $\beta$-Tubulin serves as a loading control. $B$, Hypothalamus of six each of untreated controls, lithium-treated mice, and Gsk-3 $\beta^{+/-}$mice was harvested and analyzed as in $A$, except that samples from each animal were analyzed individually. $\beta$-Catenin band intensity was measured by chemifluorescent immunoblotting and quantitation on a Storm/Phosphorlmager. ${ }^{*} p \leq 0.05$ compared with untreated wild-type mice (see Materials and Methods).

FST and hole board but also showed decreased overall activity in the hole board, muted ASR, and reduced grip strength. Therefore the LiCl-treated Gsk-3 $\beta^{+/-}$groups are not included in this analysis.) Thus, heterozygous loss of $G s k-3 \beta$ mimics lithium in two specific behavior tests without causing an overall change in state of the animals, strongly supporting the hypothesis that these behavioral effects of lithium in mice are mediated through inhibition of GSK-3 $\beta$.

\section{$\beta$-catenin accumulation in lithium-treated and Gsk-3$\beta^{+/-}$mice}

GSK-3-mediated phosphorylation of $\beta$-catenin leads to its rapid degradation. Wnt signaling causes inhibition of GSK-3, leading to stabilization and accumulation of $\beta$-catenin, and this has become a widely used assay for downstream activation of the Wnt pathway (Peifer et al., 1994) as well as for inhibition of GSK-3 in cultured cells. Therefore, inhibition of GSK-3 by lithium leads to accumulation of $\beta$-catenin protein and activation of Wnt target genes (Stambolic et al., 1996; Hedgepeth et al., 1997; Zhang et al., 2003). To confirm that GSK-3 activity is inhibited by lithium therapy in vivo, we measured $\beta$-catenin protein levels in four regions of the brain after behavioral tests were completed. Brain regions were dissected and pooled from multiple animals, and $\beta$-catenin levels were assessed by immunoblotting. Using this method, we detected an increase in $\beta$-catenin protein levels in the hypothalamus (Fig. 6A) and an apparent increase in the frontal cortex (data not shown). However, we found that when we analyzed animals individually, some of the lithium-treated mice had anomalously high levels of $\beta$-catenin; thus, pooled samples may be skewed by these outliers. We therefore analyzed groups of six animals individually for $\beta$-catenin levels and measured the protein levels by immunoblotting and quantitative chemiluminescence. Based on this analysis, we observed a $\sim 30 \%$ increase in $\beta$-catenin protein levels in the hypothalamus that was statistically significant, supporting that GSK-3 was inhibited in this region and also suggesting that downstream Wnt signaling could be activated by lithium in the CNS (Fig. 6). (The apparent increase in the cortex observed with pooled samples was not statistically significant when individual animals were analyzed; data not

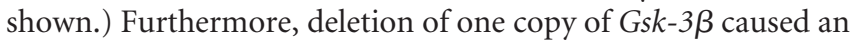
increase in $\beta$-catenin levels, and this was more pronounced in lithium-treated Gsk-3$\beta^{+/-}$mice. Variable increases were seen in the hippocampus with lithium treatment or loss of $G s k-3 \beta$, and no effect was seen in the cerebellum (data not shown).

\section{Lithium activates Wnt-dependent transcription in vivo}

The amount of cytoplasmic $\beta$-catenin that is regulated by GSK-3 usually represents a small fraction of the total cellular pool of $\beta$-catenin, and furthermore, changes in a small population of cells could be swamped out if large portions of unaffected tissues are included in the analysis. We therefore used an alternative approach to determine localized activation of Wnt signaling by lithium. Accumulation of $\beta$-catenin leads to activation of Wnt-dependent target genes mediated through a $\beta$-catenin-Tcf transcription complex. The measurement of tissue-specific activation of this pathway in mice has been facilitated by the generation of transgenic promoterreporter mouse lines that contain Wnt-responsive Tcf DNA binding elements driving $\beta$-galactosidase. For example, the BAT-gal (Maretto et al., 2003) and TOPGAL (DasGupta and Fuchs,

\section{control}
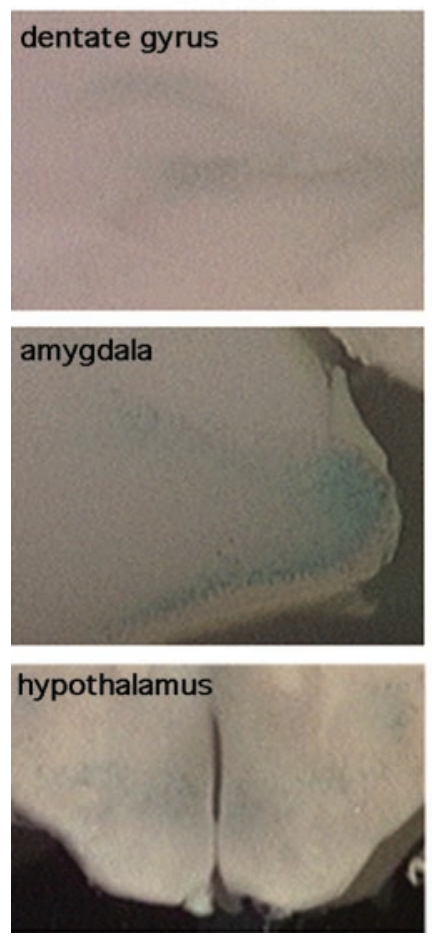

\section{Lithium}
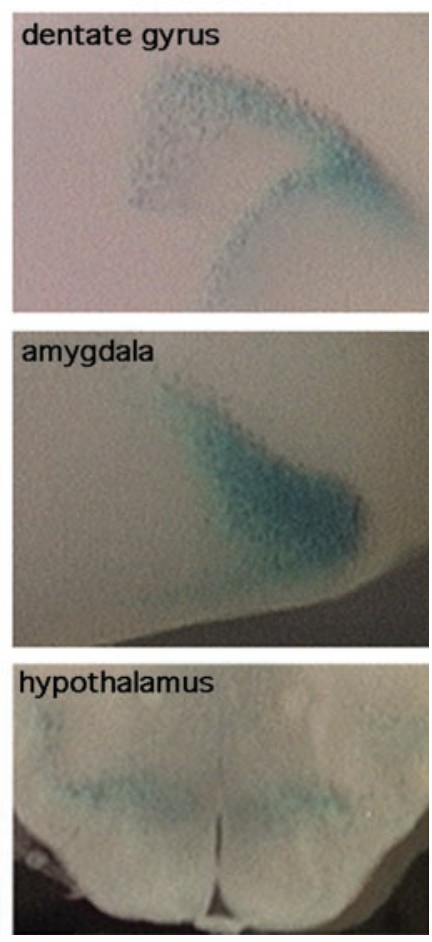

Figure 7. Increased Wnt-Tcf-dependent transcription in lithium-treated mice. Coronal vibratome sections of brains from control and lithium-treated BAT-gal mice after incubation with $\mathrm{X}$-gal. $\beta$-Galactosidase activity is increased in the dentate gyrus, amygdala, and to a lesser extent the hypothalamus. $\beta$-Galactosidase activity was exclusively in neurons (see Materials and Methods). 
1999) mouse lines have been shown to identify Wnt responsive tissues in embryos and adult mice. We therefore tested induction of Wnt-dependent transcription in response to the lithium diet in the brains of BAT-gal mice. As shown in Figure 7, BAT-gal mice given oral $\mathrm{LiCl}$ for 1 week showed greater $\beta$-galactosidase activity in the amygdala, hippocampus, and hypothalamus, consistent with the accumulation of $\beta$-catenin protein described above. The increased activity was most pronounced in the amygdala but also clearly evident in the hippocampus. Under these assay conditions, $\beta$-galactosidase activity was observed exclusively in neurons, as determined by immunostaining for neuron-specific $\beta$-tubulin, Nissl stain, and in the hippocampus, by cell size and location (see Materials and Methods). The increased activity in the hypothalamus was observed in five of six experiments but was of lower magnitude in some samples. Preliminary data suggest that $\beta$-galactosidase activity increased $\sim 3.7$-fold in the amygdala $(n=5 ; p<0.05)$ and 1.6-fold in the hippocampus $(n=4 ; p<$ $0.05)$, consistent with a previous report showing a twofold increase in $\beta$-catenin in the hippocampus of lithium-treated rats (De Ferrari et al., 2003). TOPGAL mice showed a similar increase in Wnt-dependent $\beta$-galactosidase activity in the hippocampus, amygdala, and hypothalamus and to a greater extent in the cortex, although overall $\beta$-galactosidase activity was significantly lower than in the BAT-gal line (data not shown). Under these staining conditions, $\beta$-galactosidase activity was observed in untreated BAT-gal mice but at a lower level, as shown in Figure 7 (Maretto et al., 2003). Thus, these reporter lines provide confirmation of inhibition of GSK-3 by oral lithium treatment in adult animals and provide direct in vivo evidence for lithium-mediated activation of Wnt-dependent transcription in the mammalian CNS.

\section{Discussion}

We describe simple behavior tests that are sensitive to lithium

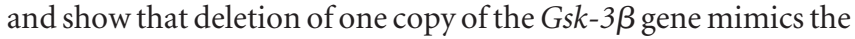
effect of lithium on these behaviors. Molecular targets of GSK-3, including $\beta$-catenin, are also affected similarly by lithium and Gsk-3 $\beta$ haploinsufficiency. These behavioral and molecular correlations strongly support the hypothesis that GSK-3 is an important target for the behavioral effects of lithium.

Lithium decreases time immobile in the FST in a robust, dosedependent manner. To our knowledge, an effect of chronic lithium in the FST has not been reported. Lithium does not affect time immobile for rats in the FST (Hata et al., 1995; Kitamura et al., 2002; Einat et al., 2003; Wegener et al., 2003). Acute lithium injection has been reported to reduce time immobile in mice if animals are tested $30 \mathrm{~min}$ after injection but not at $45 \mathrm{~min}$ (Nixon et al., 1994; Redrobe and Bourin, 1999a). Acute lithium also reportedly enhances the effect of antidepressants on the FST (Redrobe and Bourin, 1999b). In contrast, we used chronic oral lithium at clinically tolerated doses, which more closely approximates the lag time required for the clinical response to lithium in BPD patients. The FST has predictive validity as a model of antidepressant activity (Cryan et al., 2002); although lithium is used as an antimanic agent and mood stabilizer, frequently in combination with antidepressants, it is not widely used as an antidepressant alone. However, the effect of lithium in the FST could represent a parallel to the mood stabilizing action of lithium on the depressive phase of BPD. Interestingly, lithium treatment also parallels the effects of antidepressants on learned helplessness (Sherman and Petty, 1980) and immobilization stress in rats (Hata et al., 1995). We found that lithium treatment also reduced exploratory behavior, which may be consistent with observations in which lithium attenuated the effect of amphetamine-chlordiazepoxide on exploratory behavior (Murphy, 1977). Furthermore, the effect of lithium on exploratory behavior persisted when lithium was discontinued, and the effect on the FST after lithium was removed approached statistical significance. These observations are reminiscent of the time course of lithium efficacy observed in BPD (Muller-Oerlinghausen and Drescher, 1979).

Importantly, the effects of lithium in the FST and exploratory behavior were not attributable to changes in overall activity or nonspecific changes in the state of the animals. Several tests that investigated state changes revealed no differences among the groups in open field activity, distance traveled in the elevated zero maze, grip strength, accelerated rotorod, righting response, grooming, social interactions, or other home cage behaviors. In addition, ASR, prepulse inhibition of ASR, and habituation of ASR were not affected by lithium. These findings support that the effects seen in the FST and exploratory behavior are not attributable to nonspecific effects of lithium.

Strong support for GSK-3 as the relevant target of lithiummediated developmental defects has been provided by loss-offunction and dominant-negative mutations in Gsk-3 $\beta$ in Dictyostelium, Xenopus, sea urchin, zebrafish, and other organisms. In each case, the effect of lithium on development phenocopies Gsk-3 $\beta$ null and dominant-negative mutants (for review, see Phiel and Klein, 2001; Gurvich and Klein, 2002). In most cases, these developmental effects of lithium arise through activation of the Wnt pathway, which is inhibited by constitutive GSK-3 activity. Lithium mimics Wnts by inhibiting GSK-3 (Klein and Melton, 1996), stabilizing $\beta$-catenin (Stambolic et al., 1996; Hedgepeth et al., 1997), and thereby activating Wnt-dependent transcription (Zhang et al., 2003). This hypothesis is also supported by observations that alternative GSK-3 inhibitors cause similar effects on embryonic development through activation of Wnt signaling (Yost et al., 1998; Hedgepeth et al., 1999; Meijer et al., 2003).

Lithium also increases growth cone area (Lucas et al., 1998; Goold et al., 1999; Hall et al., 2000; Williams et al., 2002) and alters synaptogenesis in cultured neurons (Salinas, 1999; Hall et al., 2000). These effects of lithium mimic Wnt-dependent regulation of synaptogenesis in diverse systems (Lucas and Salinas, 1997; Salinas, 1999; Burden, 2000; Packard et al., 2002, 2003). Lithium and structurally unrelated GSK-3 inhibitors also attenuate growth cone collapse induced by semaphorin-3a (sema-3a). GSK- $3 \beta$ phosphorylated on serine- 9 (which has reduced activity) is localized to growth cones and is dephosphorylated after stimulation by sema-3a (Eickholt et al., 2002) or lysophosphatidic acid, which also induces growth cone collapse (Sayas et al., 1999). These observations support the hypothesis that GSK-3 regulates growth cone collapse and may explain growth cone stabilization by lithium in cultured neurons. However, lithium has also been proposed to affect growth cone area through depletion of inositol. Thus, addition of myo-inositol to cultured sensory neurons prevented the effects of lithium (as well as other mood stabilizing drugs) on growth cone area (Williams et al., 2002), an intriguing observation that led those authors to propose that lithium and other mood stabilizers act in this setting through a common mechanism involving depletion of myo-inositol. However, several other reports, using similar cell types, found no effect of myo-inositol on lithium-induced changes in growth cone area (Lucas and Salinas, 1997; Lucas et al., 1998; Hall et al., 2000). The reasons for these differences are not clear, but it should be noted that exogenous inositol can have indirect effects not obviously 
related to depletion of myo-inositol (Hedgepeth et al., 1997; Shaldubina et al., 2002).

Because multiple potential targets of lithium are present in neurons, and because these targets have not been examined in behavior models, we tested whether genetic disruption of Gsk-3 $\beta$ would mimic the behavioral effects of lithium. Although Gsk$3 \beta^{-/-}$mice die in utero, Gsk-3$\beta^{+/-}$mice are viable, express reduced levels of GSK-3 $\beta$ protein, and have reduced GSK-3 activity. Remarkably, the effect of lithium is mimicked in the GSK $-3 \beta^{+/-}$mice, with a marked decrease in time immobile on the FST test and reduced exploratory behavior. As with lithium, the behavior of GSK-3 $\beta^{+/-}$mice in the FST and hole board apparatus is not caused by changes in overall activity. Consistent with these observations, we also observed similar effects on the FST and exploratory behavior in transgenic mice expressing a dominant-negative form of GSK-3 $\beta$ in the postnatal brain (W. T. O'Brien and P. S. Klein, unpublished data).

Loss of Gsk-3 $\beta$ also mimicked the molecular effects of lithium.

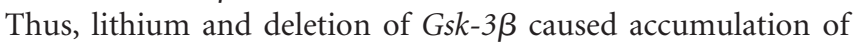
$\beta$-catenin protein, a well established consequence of GSK-3 inhibition. Inhibition of GSK-3 and accumulation of $\beta$-catenin are associated with activation of Wnt-regulated gene expression, and we found that a Wnt/Tcf-dependent reporter was also activated in vivo by lithium treatment in the amygdala, hippocampus, and hypothalamus, consistent with our observations with $\beta$-catenin.

These observations support that oral lithium inhibits neuronal GSK-3 in vivo and are consistent with previous reports showing in vivo inhibition of neuronal GSK-3 by lithium, as assessed by reduced tau phosphorylation, accumulation of $\beta$-catenin protein (as described above), inhibition of GSK- $3 \alpha$-mediated processing of the amyloid precursor protein, and increased phosphorylation of GSK-3 (Munoz-Montano et al., 1997; De Sarno et al., 2002; Ghribi et al., 2002; De Ferrari et al., 2003; Pérez et al., 2003; Phiel et al., 2003; Ryder et al., 2003). For example, lithium has been shown to cause increased phosphorylation of aminoterminal serines in GSK- $3 \alpha$ and $\beta$ (Chalecka-Franaszek and Chuang, 1999; Bhat et al., 2000; Lochhead et al., 2001; De Sarno et al., 2002; Hall et al., 2002; Song et al., 2002; Zhang et al., 2003). We recently demonstrated that this inhibitory phosphorylation is a secondary consequence of direct inhibition of GSK-3 by lithium or other agents (Zhang et al., 2003); although increased GSK-3 phosphorylation was not observed in brains from heterozygous mice (data not shown), embryonic fibroblasts derived from homozygous Gsk-3 $\beta$ knock-out embryos show increased $\mathrm{N}$-terminal phosphorylation of GSK-3 $\alpha$ (Chalecka-Franaszek and Chuang, 1999; Bhat et al., 2000; Lochhead et al., 2001; De Sarno et al., 2002; Hall et al., 2002; Song et al., 2002; Zhang et al., 2003). The intriguing observation that GSK-3 phosphorylation is increased in the brains of lithium-treated mice (De Sarno et al., 2002) provides additional support for direct inhibition of GSK-3 by lithium in vivo.

Lithium inhibits both $\alpha$ and $\beta$ isoforms of GSK-3 (Klein and Melton, 1996; Stambolic et al., 1996), and thus the behavioral effects of lithium observed here could arise through inhibition of either or both forms of GSK-3. Loss of one copy of Gsk-3 $\beta$ would be expected to reduce overall GSK-3 by $25 \%$ in regions where the $\alpha$ and $\beta$ isoforms are expressed at equal level and by $50 \%$ in regions where $G s k-3 \beta$ is expressed exclusively. Thus, although the data presented here demonstrate a role for GSK-3 $\beta$ in the regulation of specific mouse behaviors, GSK- $3 \alpha$ may also play a role in this regulation: the relative contribution of these closely related isoforms to lithium-sensitive behaviors can be addressed only when the GSK-3 $\alpha$ knock-out mouse becomes available.
Thus, we found a strong behavioral and molecular correlation between the in vivo effects of lithium and genetic disruption of $G s k-3 \beta$, strongly supporting the hypothesis that GSK-3 $\beta$ is an important neuronal target for the behavioral effects of lithium.

\section{References}

Belmaker RH, Kofman O (1990) Lithium research: state of the art. Biol Psychiatry 27:1279-1281.

Berridge MJ, Downes CP, Hanley MR (1989) Neural and developmental actions of lithium: a unifying hypothesis. Cell 59:411-419.

Bhat RV, Shanley J, Correll MP, Fieles WE, Keith RA, Scott CW, Lee CM (2000) Regulation and localization of tyrosine216 phosphorylation of glycogen synthase kinase-3beta in cellular and animal models of neuronal degeneration. Proc Natl Acad Sci USA 97:11074-11079.

Burden SJ (2000) Wnts as retrograde signals for axon and growth cone differentiation. Cell 100:495-497.

Chalecka-Franaszek E, Chuang DM (1999) Lithium activates the serine/ threonine kinase Akt-1 and suppresses glutamate-induced inhibition of Akt-1 activity in neurons. Proc Natl Acad Sci USA 96:8745-8750.

Cox C, Harrison RP, Steinberg H, Tomkiewicz M (1971) Lithium attenuates drug-induced hyperactivity in rats. Nature 232:336-338.

Crawley JN (2000) What's wrong with my mouse? Behavioral phenotyping of transgenic and knockout mice, Chap 3, 4, 10. New York: Wiley.

Crawley JN, Paylor R (1997) A proposed test battery and constellations of specific behavioral paradigms to investigate the behavioral phenotypes of transgenic and knockout mice. Horm Behav 31:197-211.

Cryan JF, Markou A, Lucki I (2002) Assessing antidepressant activity in rodents: recent developments and future needs. Trends Pharmacol Sci 23:238-245.

DasGupta R, Fuchs E (1999) Multiple roles for activated LEF/TCF transcription complexes during hair follicle development and differentiation. Development 126:4557-4568.

Davies C, Sanger DJ, Steinberg H, Tomkiewicz M, U’Prichard DC (1974) Lithium and alpha-methyl-p-tyrosine prevent "manic" activity in rodents. Psychopharmacologia 36:263-274.

De Ferrari GV, Chacon MA, Barria MI, Garrido JL, Godoy JA, Olivares G, Reyes AE, Alvarez A, Bronfman M, Inestrosa NC (2003) Activation of Wnt signaling rescues neurodegeneration and behavioral impairments induced by beta-amyloid fibrils. Mol Psychiatry 8:195-208.

De Sarno P, Li X, Jope RS (2002) Regulation of Akt and glycogen synthase kinase-3beta phosphorylation by sodium valproate and lithium. Neuropharmacology 43:1158-1164.

Eickholt BJ, Walsh FS, Doherty P (2002) An inactive pool of GSK-3 at the leading edge of growth cones is implicated in Semaphorin 3A signaling. J Cell Biol 157:211-217.

Einat H, Yuan P, Gould TD, Li J, Du J, Zhang L, Manji HK, Chen G (2003) The role of the extracellular signal-regulated kinase signaling pathway in mood modulation. J Neurosci 23:7311-7316.

Faria MS, Teixeira NA (1993) Reversal of learned helplessness by chronic lithium treatment at a prophylactic level. Br J Med Biol Res 26:1201-1212.

File SE, Wardill AG (1975) The reliability of the hole-board apparatus. Psychopharmacologia 44:47-51.

Ghribi O, Herman MM, Spaulding NK, Savory J (2002) Lithium inhibits aluminum-induced apoptosis in rabbit hippocampus, by preventing cytochrome $\mathrm{c}$ translocation, Bcl-2 decrease, Bax elevation and caspase- 3 activation. J Neurochem 82:137-145.

Goold RG, Owen R, Gordon-Weeks PR (1999) Glycogen synthase kinase 3beta phosphorylation of microtubule-associated protein $1 \mathrm{~B}$ regulates the stability of microtubules in growth cones. J Cell Sci 112:3373-3384.

Gurvich N, Klein PS (2002) Lithium and valproic acid: parallels and contrasts in diverse signaling contexts. Pharmacol Ther 96:45-66.

Hall AC, Lucas FR, Salinas PC (2000) Axonal remodeling and synaptic differentiation in the cerebellum is regulated by WNT-7a signaling. Cell 100:525-535.

Hall AC, Brennan A, Goold RG, Cleverley K, Lucas FR, Gordon-Weeks PR, Salinas PC (2002) Valproate regulates GSK-3-mediated axonal remodeling and synapsin I clustering in developing neurons. Mol Cell Neurosci 20:257-270.

Hata T, Itoh E, Nishikawa H (1995) Behavioral characteristics of SARTstressed mice in the forced swim test and drug action. Pharmacol Biochem Behav 51:849-853.

Hedgepeth C, Conrad L, Zhang Z, Huang H, Lee V, Klein P (1997) Activa- 
tion of the Wnt signaling pathway: a molecular mechanism for lithium action. Dev Biol 185:82-91.

Hedgepeth CM, Deardorff MA, Rankin K, Klein PS (1999) Regulation of glycogen synthase kinase 3 beta and downstream Wnt signaling by axin. Mol Cell Biol 19:7147-7157.

Hoeflich KP, Luo J, Rubie EA, Tsao MS, Jin O, Woodgett JR (2000) Requirement for glycogen synthase kinase-3beta in cell survival and NF-kappaB activation. Nature 406:86-90.

Kitamura Y, Araki H, Gomita Y (2002) Influence of ACTH on the effects of imipramine, desipramine and lithium on duration of immobility of rats in the forced swim test. Pharmacol Biochem Behav 71:63-69.

Klein PS, Melton DA (1996) A molecular mechanism for the effect of lithium on development. Proc Natl Acad Sci USA 93:8455-8459.

Kofman O, Levin U, Alpert C (1995) Lithium attenuates hypokinesia induced by immobilization stress in rats. Prog Neuropsychopharmacol Biol Psychiatry 19:1081-1090.

Lenox RH, Gould TD, Manji HK (2002) Endophenotypes in bipolar disorder. Am J Med Genet 114:391-406.

Lochhead PA, Coghlan M, Rice SQ, Sutherland C (2001) Inhibition of GSK-3 selectively reduces glucose-6-phosphatase and phosphatase and phosphoenolypyruvate carboxykinase gene expression. Diabetes 50:937-946.

Lucas FR, Salinas PC (1997) WNT-7a induces axonal remodeling and increases synapsin I levels in cerebellar neurons. Dev Biol 192:31-44.

Lucas FR, Goold RG, Gordon-Weeks PR, Salinas PC (1998) Inhibition of GSK3beta leading to the loss of phosphorylated MAP-1B is an early event in axonal remodelling induced by WNT-7a or lithium. J Cell Sci 111:1351-1361.

Manji HK, Chen G, Hsiao JK, Risby ED, Masana MI, Potter WZ (1996) Regulation of signal transduction pathways by mood-stabilizing agents: implications for the delayed onset of therapeutic efficacy. J Clin Psychiatry 57:34-46.

Maretto S, Cordenonsi M, Dupont S, Braghetta P, Broccoli V, Hassan AB, Volpin D, Bressan GM, Piccolo S (2003) Mapping Wnt/beta-catenin signaling during mouse development and in colorectal tumors. Proc Natl Acad Sci USA 100:3299-3304.

Meijer L, Skaltsounis AL, Magiatis P, Polychronopoulos P, Knockaert M, Leost M, Ryan XP, Vonica CA, Brivanlou A, Dajani R, Crovace C, Tarricone C, Musacchio A, Roe SM, Pearl L, Greengard P (2003) GSK-3selective inhibitors derived from Tyrian purple indirubins. Chem Biol 10:1255-1266.

Muller-Oerlinghausen B, Drescher K (1979) Time course of clinicalchemical parameters under long-term lithium treatment. Int J Clin Pharmacol Biopharm 17:228-235.

Munoz-Montano JR, Moreno FJ, Avila J, Diaz-Nido J (1997) Lithium inhibits Alzheimer's disease-like tau protein phosphorylation in neurons. FEBS Lett 411:183-188.

Murphy DL (1977) Animal models for mania. In: Animal models in psychiatry and neurology (Hanin IUE, ed), pp 211-223. Oxford: Pergammon.

Nixon MK, Hascoet M, Bourin M, Colombel MC (1994) Additive effects of lithium and antidepressants in the forced swimming test: further evidence for involvement of the serotoninergic system. Psychopharmacology 115:59-64.

Packard M, Koo E, Gorczyca M, Sharpe J, Cumberledge S, Budnik V (2002) The Drosophila Wnt, wingless, provides an essential signal for pre- and postsynaptic differentiation. Cell 111:319-330.

Packard M, Mathew D, Budnik V (2003) Wnts and TGF beta in synaptogenesis: old friends signalling at new places. Nat Rev Neurosci 4:113-120.

Paxinos G, Franklin KBJ (2001) The mouse brain in stereotaxic coordinates, Ed 2. San Diego: Academic.

Peifer M, Sweeton D, Casey M, Wieschaus E (1994) Wingless signal and
Zeste-white 3 kinase trigger opposing changes in the intracellular distribution of Armadillo. Development 120:369-380.

Pérez M, Hernández F, Lim F, Díaz-Nido J, Avila J (2003) Chronic lithium treatment decreases mutant tau protein aggregation in a transgenic mouse model. J Alzheimers Dis 5:301-308.

Phiel CJ, Klein PS (2001) Molecular targets of lithium action. Annu Rev Pharmacol Toxicol 41:789-813.

Phiel CJ, Wilson CA, Lee VM, Klein PS (2003) GSK-3alpha regulates production of Alzheimer's disease amyloid-beta peptides. Nature 423:435-439.

Poitou P, Boulu R, Bohuon C (1975) Effect of lithium and other drugs on the amphetamine chlordiazeposice hyperactivity in mice. Experientia 31:99-101.

Porsolt RD, Bertin A, Jalfre M (1977) Behavioral despair in mice: a primary screening test for antidepressants. Arch Int Pharmacodyn Ther 229:327-336.

Redrobe JP, Bourin M (1999a) The effect of lithium administration in animal models of depression: a short review. Fundam Clin Pharmacol 13:293-299.

Redrobe JP, Bourin M (1999b) Evidence of the activity of lithium on 5-HT1B receptors in the mouse forced swimming test: comparison with carbamazepine and sodium valproate. Psychopharmacology 141:370-377.

Ryder J, Su Y, Liu F, Li B, Zhou Y, Ni B (2003) Divergent roles of GSK3 and CDK5 in APP processing. Biochem Biophys Res Commun 312:922-929.

Salinas PC (1999) Wnt factors in axonal remodelling and synaptogenesis. Biochem Soc Symp 65:101-109.

Sayas CL, Moreno-Flores MT, Avila J, Wandosell F (1999) The neurite retraction induced by lysophosphatidic acid increases Alzheimer's diseaselike Tau phosphorylation. J Biol Chem 274:37046-37052.

Shaldubina A, Ju S, Vaden DL, Ding D, Belmaker RH, Greenberg ML (2002) Epi-inositol regulates expression of the yeast INO1 gene encoding inositol-1-P synthase. Mol Psychiatry 7:174-180.

Sherman AD, Petty F (1980) Neurochemical basis of the action of antidepressants on learned helplessness. Behav Neural Biol 30:119-134.

Song L, De Sarno P, Jope RS (2002) Central role of glycogen synthase kinase-3beta in endoplasmic reticulum stress-induced caspase-3 activation. J Biol Chem 277:44701-44708.

Stambolic V, Ruel L, Woodgett J (1996) Lithium inhibits glycogen synthase kinase- 3 activity and mimics wingless signalling in intact cells. Curr Biol 6:1664-1668.

Tao YS, Edwards RA, Tubb B, Wang S, Bryan J, McCrea PD (1996) betaCatenin associates with the actin-bundling protein fascin in a noncadherin complex. J Cell Biol 134:1271-1281.

Wegener G, Bandpey Z, Heiberg IL, Mork A, Rosenberg R (2003) Increased extracellular serotonin level in rat hippocampus induced by chronic citalopram is augmented by subchronic lithium: neurochemical and behavioural studies in the rat. Psychopharmacology 166:188-194.

Williams RS, Cheng L, Mudge AW, Harwood AJ (2002) A common mechanism of action for three mood-stabilizing drugs. Nature 417:292-295.

Wood AJ, Goodwin GM, De Souza R, Green AR (1986) The pharmacokinetic profile of lithium in rat and mouse; an important factor in psychopharmacological investigation of the drug. Neuropharmacology 25:1285-1288.

York JD, Ponder JW, Majerus PW (1995) Definition of a metal-dependent/ $\mathrm{Li}(+)$-inhibited phosphomonoesterase protein family based upon a conserved three-dimensional core structure. Proc Natl Acad Sci USA 92:5149-5153.

Yost C, Farr GHr, Pierce SB, Ferkey DM, Chen MM, Kimelman D (1998) GBP, an inhibitor of GSK-3, is implicated in Xenopus development and oncogenesis. Cell 93:1031-1041.

Zhang F, Phiel CJ, Spece L, Gurvich N, Klein PS (2003) Inhibitory phosphorylation of glycogen synthase kinase-3 (GSK-3) in response to lithium. Evidence for autoregulation of GSK-3. J Biol Chem 278:33067-33077. 